\title{
A critical view of magnetic resonance imaging in the evaluation of motor neuron diseases
}

\author{
Uma visão crítica da ressonância nuclear magnética na avaliação das doenças do neurônio motor
}

Cláudia da Costa Leite

\author{
MD, PhD; Neuroradiologist, \\ Associated Professor of the \\ Departament of Radiology \\ at Faculdade de Medicina of \\ Universidade de São Paulo (USP), \\ São Paulo SP, Brazil. \\ Correspondence \\ Cláudia da Costa Leite \\ Instituto de Radiologia, Setor de \\ Ressonância Magnética \\ Rua Doutor Enéas de Carvalho \\ Aguiar $255 /$ portaria $5 / 3^{\circ}$ andar \\ 05403-001 São Paulo SP - Brasil \\ E-mail:claudia.leite@hc.fm.usp.br \\ Conflict of interest \\ There is no conflict of interest to \\ declare. \\ Received 09 May 2012 \\ Accepted 16 May 2012
}

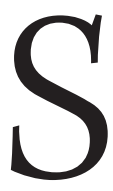
ome neurodegenerative diseases, such as Alzheimer and amyotrophic lateral sclerosis (ALS) or primary LS (PLS), do not have specific magnetic resonance imaging (MRI) findings or these findings are inconsistent, especially in their early stages. In this setting, MRI plays a role in the exclusion of other diagnosis, which could explain the clinical picture and give support for a clinical diagnosis of these entities.

New MRI techniques, also known as nonconventional or functional, have been used especially in the research field, trying to help in the early diagnosis of these neurodegenerative diseases and also as tools to monitor disease evolution and response to treatment. Sometimes, they can give additional information disclosing an extent of brain involvement, which is not evident using conventional MRI sequences, giving new insights in the understanding of their pathophysiology. The use of new imaging modalities aim at doing their earlier diagnosis ${ }^{1,2}$.

As MRI is a noninvasive and reproducible imaging method, it has been extensively applied to neurologic diseases. Nonconventional MRI techniques has been used in the assessment of multiple sclerosis and their use was expanded from the research field to drug trials and clinical practice. Magnetization transfer contrast, diffusion tensor imaging, proton spectroscopy, functional MRI, and volumetric techniques have been used to detect brain abnormalities in normal appearing white and gray matter and to evaluate function compromise or brain regional atrophy in multiple sclerosis ${ }^{3}$. The extended application of these techniques for other neurological diseases may improve diagnosis and understanding of brain involvement.

ALS/PLS is a neurodegenerative disease that affects the motor system. Clinical manifestations are related to compromise of upper and lower motor neurons. The standard diagnostic criteria for ALS/PLS, proposed by Brooks et al. ${ }^{4}$, are based on clinical findings. The most recent Awaji criteria ${ }^{5}$ associate electromyography findings and clinical manifestations for ALS/PLS diagnosis; however, imaging findings are not considered in these criteria.

Conventional MRI findings are not considered in the criteria for the diagnosis of ALS/ PLS since they are not always present, and many times they are not specific (sometimes they are also identified in the normal population) ${ }^{1}$. The main role of conventional MRI nowadays is still to detect structural lesions that can exclude the diagnosis of ALS/PLS.

This issue of Arquivos de Neuro-Psiquiatria presents a very interesting review by Rocha and Maia Jr. of MRI findings in ALS/PLS that is focused on conventional and nonconventional MRI techniques, such as magnetization transfer contrast (MTC), proton spectroscopy (MRS), diffusion tensor imaging (DTI), and voxel-based morphometry (VBM) ${ }^{6}$. This article shows a critical discussion of the clinical application of these techniques in ALS/PLS in the early diagnosis, as well as in the follow-up and in the treatment control of these patients. 


\section{References}

1. Johnson KA, Fox NC, Sperling RA, Klunk WE. Brain imaging in Alzheimer disease. Cold Spring Harb Perpect Med 2012;2:a006213.

2. Agosta F, Chio A, Cosottini M, et al. The present and future of neuroimaging in amyothropic lateral sclerosis. AJNR Am J Neuroradiol 2012;31:1769-1777.

3. Fillipi M, Rocca MA, Barkhof F, et al. Association between pathological and MRI findings in multiple sclerosis. Lancet Neurol 2012:11:349-360.

4. Brooks BR, Miller RG, Swash M, Munsat TL. World Federation of Neurology Research Group on Motor Neuron D. El escorial revisited: revised criteria for the diagnosis of amyotrophic lateral sclerosis and other motor neuron disorders. Amyotroph Lateral Scler Other Motor Neuron Disord 2000;1:293-299.

5. De Carvalho M, Dengler R, Eisen A, et al. The Awaji criteria for diagnosis of ALS. Muscle Nerve 2011;43:461-463.

6. Rocha AJ, Maia Júnior ACM. Is magnetic resonance imaging a plausible biomarker for upper motor neuron degeneration in amyotrophic lateral sclerosis/primary lateral sclerosis or merely a useful paraclinical tool to exclude mimic syndromes? A critical review of imaging applicability in clinical routibe. Arq Neuropsiquiatr 2012;70:532-539. 